\title{
Mobile Application Development for Quran Verse Recognition and Interpretations
}

\author{
http://dx.doi.org/10.3991/ijim.v9i1.4171 \\ M. Alqahtani and A. Fayyoumi \\ Al Imam Mohammad Ibn Saud Islamic University (IMSIU), Riyadh, Saudi Arabia
}

\begin{abstract}
Mobile learning or "m-learning" is the process of learning when learners are not at a fixed location or time and can exploit the advantage of learning opportunities using mobile technologies. Nowadays, speech recognition is being used in many mobile applications. Speech recognition helps people to interact with the device as if were they talking to another person. This technology helps people to learn anything using computers by promoting self-study over extended periods of time. The objective of this study focuses on designing and developing a mobile application for the Arabic recognition of spoken Quranic verses. The application is suitable for Android-based devices. The application is called Say Quran and is available on Google Play Store. Moreover, this paper presents the results of a preliminary study to gather feedback from students regarding the developed application.
\end{abstract}

Index Terms-Arabic Speech Recognition, automatic speech recognition (ASR), mobile application, mobile learning, Say Quran

\section{INTRODUCTION}

Traditionally, education has been offered in classes where students can interact with teachers directly. So, the physical presence of students is very important. However, the wide distribution of computers and communication technologies has made the learning process easier. Since the arrival of mobile phones in the 1980s [1], they have been vastly used by people of all ages all over the world. Actually, the whole world is becoming mobile. As a matter of fact, mobile phones are not only communication devices, but they are also portable and private equipment. Mobile technology, such as notebooks and other mobile devices (e.g., smartphones, PDAs, and tablets), constitute a type of cellular communication technology.

Nowadays, mobile technologies are becoming increasingly ubiquitous and networked. Such technologies can have a great impact on the learning purposes as well as on other purposes. There are new possibilities that have been used in education systems as a result of technological advancement. The Internet helps students to access learning resources and online courses of a broad knowledge base. Moreover, as a result of the great progress in computer technologies, especially in computer networks and the new mobile devices, this new learning concept has emerged. The demand for having learning resources available anywhere and at any time has created the need for a new form of electronic learning called mobile learning [2].

The need for mobile applications is increasing. The mobile application industry is growing fast. According to a new market research report, the total global mobile application market is expected to be worth $\$ 25$ billion by
$2015,20.5 \%$ of which will be generated by the Apple App Store [3].

Many applications have been developed for mobile platforms. Over the last few years, these applications have been the focus of technical interest, as well as market and business campaigns. One of the major application areas is educational. Moreover, within the context of Saudi Arabia the teaching of the holy Quran is a mandatory subject in many universities. Many applications exist for translating the Quran into several languages. In addition, there are applications for helping a user listen to and read the Quran, as well as search for a particular word or phrase in the text.

Recently, voice recognition trends have been widely used in different mobile applications in order to offer better interaction and usability to the user. Quran verses are composed of several words of different lengths. Usually, these verses are read in a continuous reading-style.

Therefore, recognizing Quranic verses requires an Arabic continuous speech recognition algorithm. Arabic speech recognition has faced many problems and recognizing Quranic verses is a challenging process compared to formal Arabic speeches due to the melody and Tajweed (rules for pronunciation of Quranic verses) [4]. There are many researches explaining how to recognize Arabic speech [5], [6]. However, few researches have focused on the recognition of Quranic verses.

Therefore, the objective of this study is to further develop an existing Android mobile application called Say Quran. This application depends on an algorithm of Google's application programming interface (API). The following sections present the features of the developed application. Then the paper describes the usage of the application. Next is the feedback collection method that was used. Finally, we give the conclusion and future work section.

\section{Challenges of ARABIC SPEECH RECOGNITION}

In the information age, speech recognition is developing as an important field of human computer interaction. The system of speech recognition is composed of two modules: the recognition engine module and the speech features extraction module. There are many researches in speech recognition including speech recognition engine technologies such as artificial neural networks (ANNs), hidden Markov model (HMM) and support vector machines (SVMs) [7]. However, most researches have been on the subject of English; little research has been focused on Arabic. According to the previous studies, Arabic speech recognition has many disadvantages [6], [7]. One of the studies did not include any core Arabic recognizer 
and it focused on Arabic Romanized systems, where the Arabic characters are not identified as Arabic characters but as Roman characters, which then will be translated to Arabic characters. Another study used the open source SPHINX-IV model in Arabic speech recognition by building the language and acoustic models without Romanization for the Arabic speech. But the study never used its technology for mobile applications and it should also have more Arabic words. There are many difficulties when dealing with the Arabic features in the Holy Quran such as Tajweed, which can reflect the proper pronunciation during recitation. Also, there are many diacritical signs that reflect differences of pronunciation such as "Shadda" and "Tanween." Google has built a commercial automatic speech recognition (ASR) product for Arabic. This product can support voice search, dictation, and voice control for the general Arabic-speaking public, including support for multiple Arabic dialects. Therefore, this research will focus on using the Arabic ASR by Google to develop the mobile application.

\section{APPLICATION FEATURES}

Mobile applications developments have enabled different types of users to carry out many tasks such as social networking, self-learning, gaming, Internet access, and others [8]. Actually, many researches have proved that learning using mobile technologies can have a positive effect on students [9]. The development of mobile learning applications appears to focus on using template-based application development kits provided by the developers of platforms such as Google's Android, Apple's iOS, or Nokia's Symbian. There should be a model or design pattern made by platform developers to develop applications that can fit to the platform. In addition, application developers can provide the specifications of the mobile application and these should be suitable to the design pattern and generation of code [10].

This research will focus on designing and developing a mobile application for verbal Quranic verse recognition and identification by listening to part of the verse. This application will facilitate learning the holy Quran. Moreover, it will assist users in efficiently understanding the correct meaning of Quranic verses. In addition, the application will provide the users with an alternative way to study the Quran, by simply saying the verse, which would give the user the position, translation, and interpretation of the verse.

The application focuses on developing an Android application that would make use of the ASR API that is available in the Android OS. The application was implemented using Android Jelly Bean 4.1.2. It needs an Internet connection in order to work properly since it needs to run Google's ASR engine. The application's layout is developed by using Google Layout UI. It also consists of Quran XML, Translation XML, and Interpretation XML, which is being parsed to the SQL Lite Database.

We imagine that the Quran mobile application can be used to identify Arabic speech through the device's microphone, and then the speech will go through the ASR engine to be analyzed to text and then will return the results. Then, the application would start a search loop through the Holy Quran to look for the verses with contents that are similar to the spoken words. Those results would be brought back to the user. Subsequently, the verse, the name of the Surah (chapter), and the verse's number would be shown to the user.

The user can select the appropriate language of interpretation and select the context he wants; the application would then give him a representation of that verse's interpretation and translation to many languages. Since Arabic is a verbal language developing an Arabic ASR application is considered a very big challenge since there is not enough material on this subject. The following figures can represent the steps of working on the Say Quran App. Figure 1 shows the verse insertion process, and Figure 2 shows the results in two languages with the basic information provided about the verse (in which chapter and the number of verse within the chapter). Lastly, Figure 3 shows part of the list of different languages that can be selected to show the interpretations.

\section{ARCHITECTURAL DESIGN OF SAY QURAN APPLICATION}

Figure 4 represents the architectural design of the Say Quran Application in detail. It shows the procedure of processing the user's speech via the ASR engine. Moreover, the process is going through five basic entities, which are the user, interface of the application, core class of the application that contains all the core functions related to the functional requirements, ASR engine, and the database that contains the Holy Quran in text linked with the translation and interpretation.

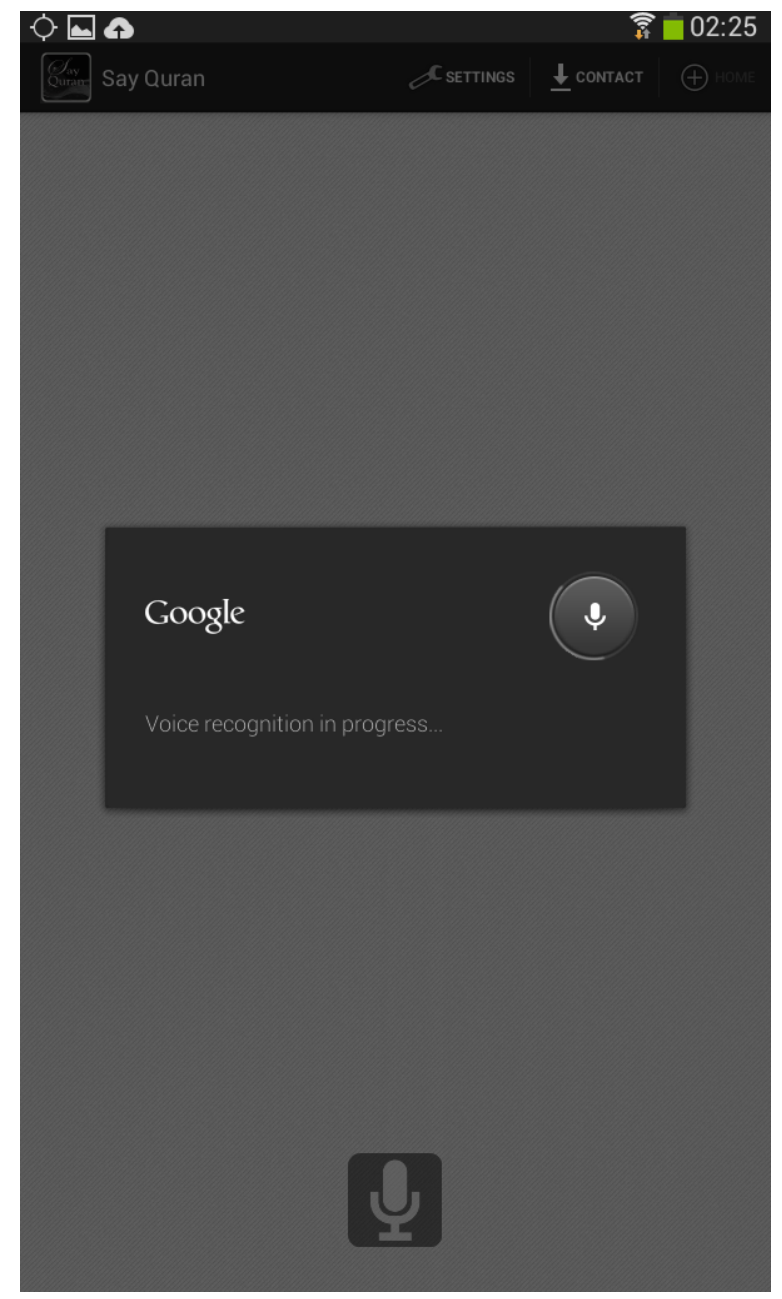

Figure 1. User's speech is processed by the ASR engine 


\section{Methodology}

This preliminary research aimed at providing an innovative solution to students and providing them with a better learning experience. It has targeted students who are studying the Holy Quran course at Al Imam Mohammed Ibn Saud Islamic University, in Riyadh. The experiment involved students at the College of Computer Sciences and Information Systems (CCIS) who are studying the subject of the Holy Quran. The application is running on an Android tablet and is ready to be used by students. The Say Quran application is available at Google Play Store.

The researcher, with the help of the course instructor, asked the students to download the application and use it for two months before gathering their feedback.

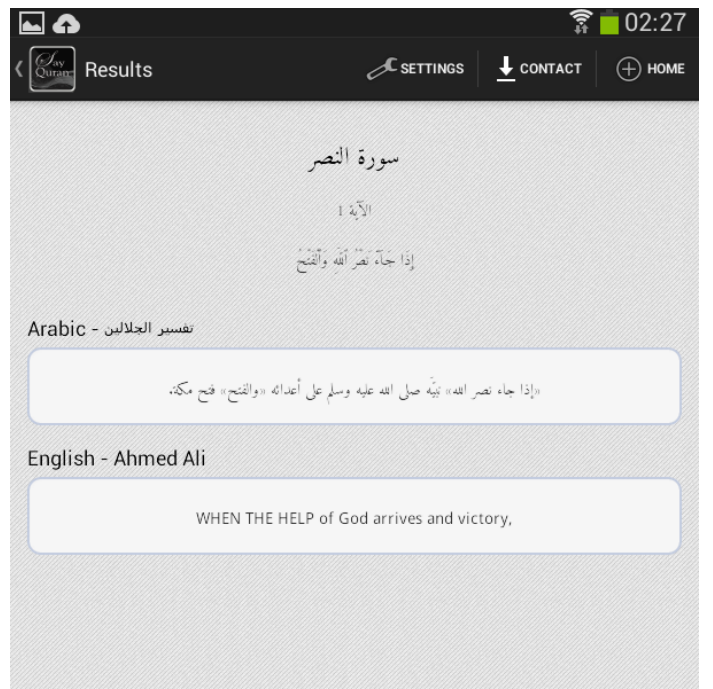

Figure 2. Quran Verse, Verse Number, Surah/Chapter Name and Interpretation

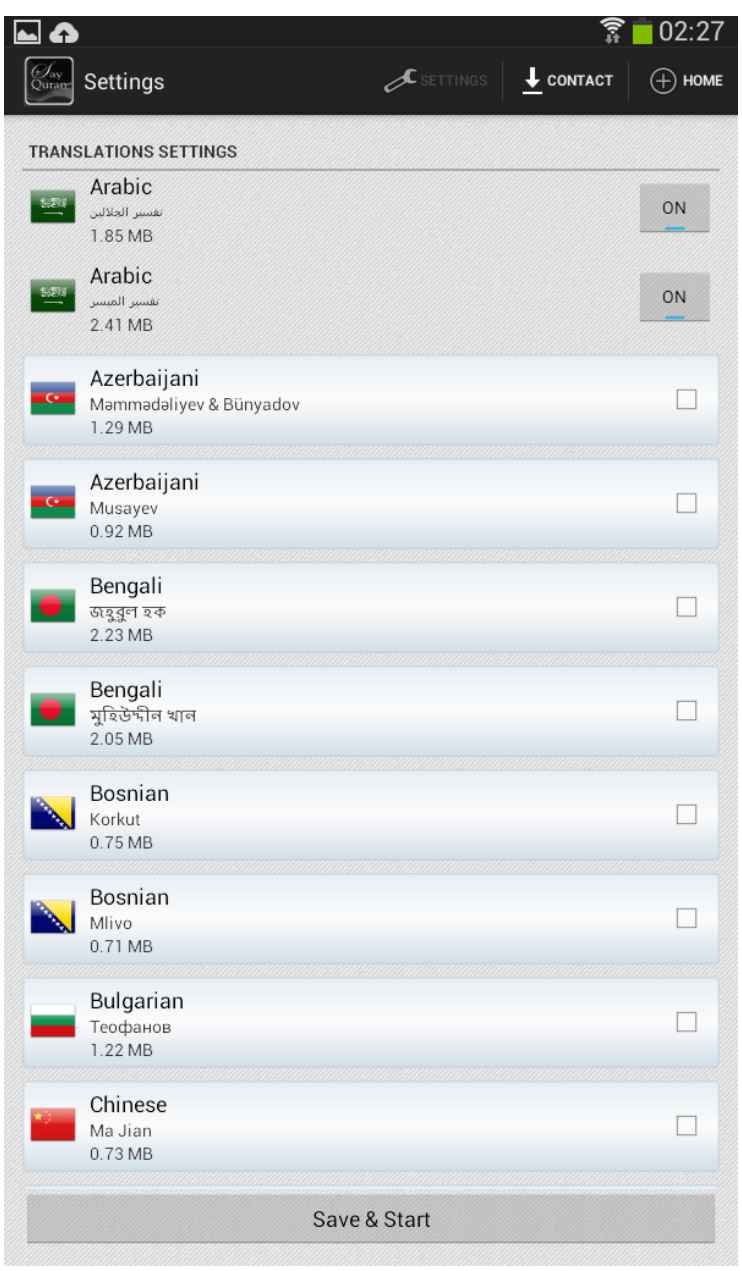

Figure 3. Settings of Translation

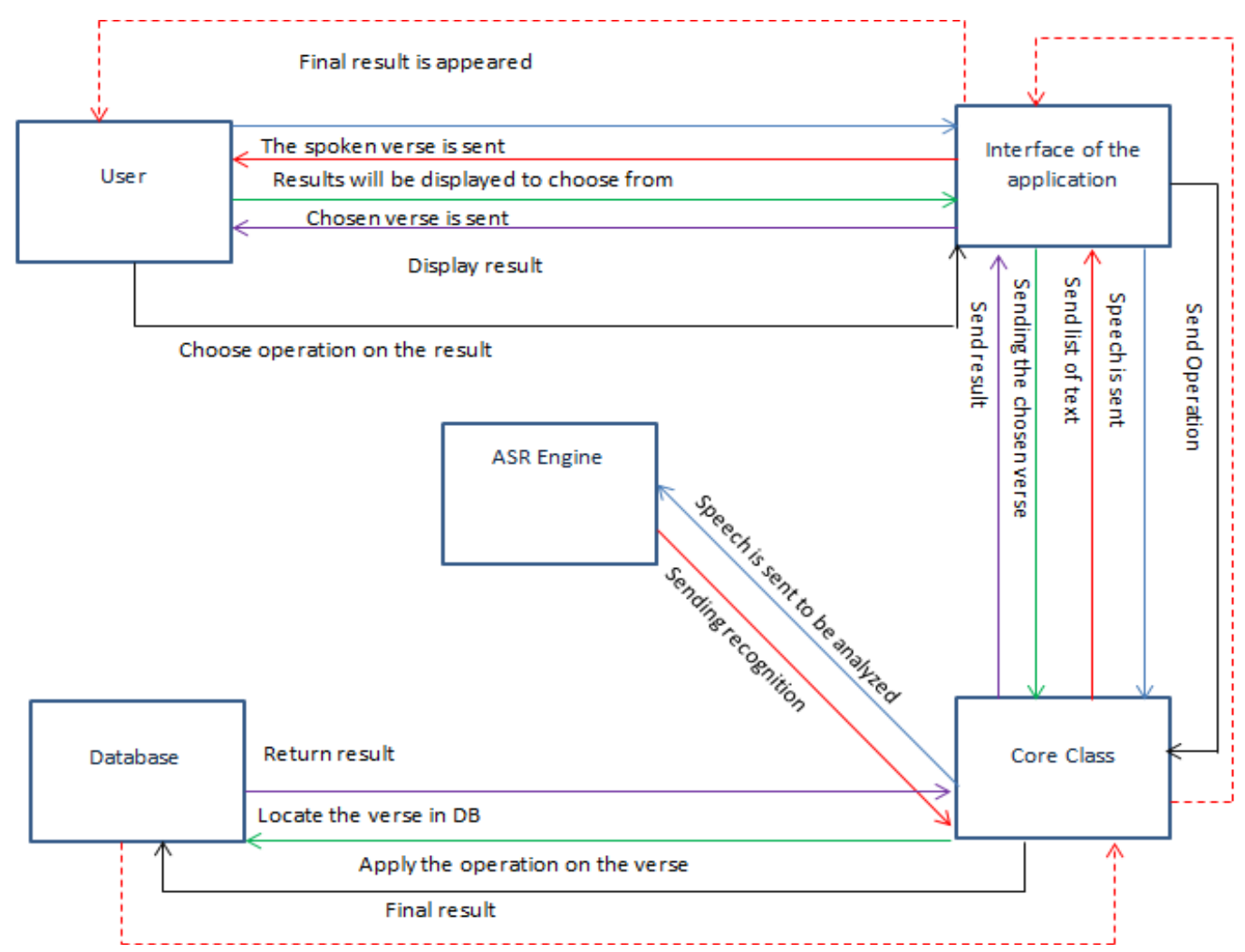

Figure 4. Say Quran Architectural Design 
During this preliminary study, interviews were conducted with 23 students to understand their attitudes toward mobile learning. Table 1 shows the questions that were asked in the face-to-face interview with students.

TABLE I.

RESEARCH INTERVIEW QUESTIONS

\begin{tabular}{|c|l|}
\hline Q\# & \multicolumn{1}{|c|}{ Interview questions } \\
\hline Q1 & Do you know what mobile learning is? \\
\hline Q2 & $\begin{array}{l}\text { Do you have a mobile device that can help you download } \\
\text { applications? }\end{array}$ \\
\hline Q3 & $\begin{array}{l}\text { What kinds of applications do you prefer to install on your } \\
\text { device? }\end{array}$ \\
\hline Q4 & $\begin{array}{l}\text { Is there any subject that you study using a mobile learning } \\
\text { technique? If so, how many subjects? }\end{array}$ \\
\hline Q5 & $\begin{array}{l}\text { From your point of view, do you think that studying courses } \\
\text { anywhere and at any time is useful for students? }\end{array}$ \\
\hline Q6 & $\begin{array}{l}\text { Do you like to study the Holy Quran subject as a mobile } \\
\text { learning course? }\end{array}$ \\
\hline Q7 & $\begin{array}{l}\text { Does your mobile device, whether it is a cellular phone or } \\
\text { tablet device, have any application about the Holy Quran? }\end{array}$ \\
\hline Q8 & $\begin{array}{l}\text { If you have that application, what are the features supported } \\
\text { by the application? }\end{array}$ \\
\hline Q9 & $\begin{array}{l}\text { How do you search about any verse in the applications you } \\
\text { have? }\end{array}$ \\
\hline Q10 & $\begin{array}{l}\text { Do you prefer searching about the verse in the Holy Quran } \\
\text { using voice recognition and recognizing Arabic speech? }\end{array}$ \\
\hline Q11 & $\begin{array}{l}\text { To what extent do you think that using this application will } \\
\text { enhance your performance in the subject? }\end{array}$ \\
\hline Q12 & $\begin{array}{l}\text { Do you think that applying mobile learning at Al Imam Uni- } \\
\text { versity will be helpful to enhance students' grades? }\end{array}$ \\
\hline Q13 & $\begin{array}{l}\text { Do you think that the application is useful for other purposes } \\
\text { than the learning process? }\end{array}$ \\
\hline
\end{tabular}

The collected results show that not all students had previous knowledge about mobile learning concepts, although all of them have mobile devices and all possess some knowledge of using mobile applications for entertainment, social communication, and other purposes.

Moreover, all the students have other Holy Quran applications downloaded on their mobile/tablet devices. However, no one has any application that can recognize Arabic speech to search in the Holy Quran. This showed that students were impressed by the application and its features.

Actually, the students are looking forward to use more applications as part of the learning process in the university since it helps them learn at any time and everywhere. Unfortunately, not one subject at the university is supported by mobile applications although most students are having a good experience of using mobile applications in general. They agree that using the Say Quran application is useful and effective and will improve their learning experience and their grades.

\section{CONCLUSION AND FUTURE WORK}

Technology in the educational process is not new and mobile learning applications are becoming more pervasive [11]. Therefore, it is very necessary to understand their impact if being used in learning options. Nowadays, great efforts are being made to develop speech recognition applications for mobile devices. It helps the user to interact with the device as if he were speaking to another person. Arabic speech recognition has its challenging characteristics and many researchers have performed studies regarding them. One of them is how to recognize verbal
Quran verses. This study focuses on developing the Say Quran Android application and then studying the attitudes of students toward this application. This work can be improved and more work can be done to add modifications and additional features. The current version of the software supports only a few languages but more languages can be added in the future work. More importantly, an in-depth study of the impact of such an application on students' learning should be conducted.

\section{REFERENCES}

[1] Huet, Jean-Michel and Henri Tcheng (2010). What If Telecoms Were the Key to the Third Industrial Revolution (GlobalEdition) [Online]. Available: http://books.google.com.sa/books

[2] Fu, Fong-Ling, Rong-Chang Su, and Sheng-Chin Yu. "EGameFlow: A scale to measure learners' enjoyment of elearning games." Computers \& Education [Online]. 52(1), pp. 101-112. http://dx.doi.org/10.1016/j.compedu.2008.07.004

[3] Rohan, "World Mobile Applications Market - Advanced Technologies, Global Forecast (2010-2015)," 2011.

[4] Demuynck, Kris and Tom Laureys. A Comparison of Different approaches to Automatic Speech Segmentation. In Proc. 5th International Conference on Text, Speech and Dialogue, pages 277284, Brno, Czech Republic, September 2002. http://dx.doi.org/10.1007/3-540-46154-X_38

[5] Quinn, Clark. "mLearning: Mobile, Wireless, In-Your-Pocket Learning." in Line Zine, 2000.

[6] AbuZeina, Dia and Moustafa ElShafe,. Cross-Word Modeling for Arabic Speech Recognition. Springer, 2012. http://dx.doi.org/10.1007/978-1-4614-1213-7

[7] Alsulaiman, M., G. Muhammad, and Z. Ali, 2011. Comparison of voice features for Arabic speech recognition. In 2011 6th International Conference on Digital Information Management, ICDIM 2011. pp. 90-95.

[8] Radia, Nimish, Ying Zhang, Mallik Tatipamula, and Vijay K. Madisetti. "Next-Generation Applications on Cellular Networks: Trends, Challenges, and Solutions," Proceedings of the IEEE , vol.100, no.4, pp. 841, 854, April 2012.

[9] Al-FAHAD, Fahad N. "Students' Attitudes and Perceptions towards the Effectiveness of Mobile Learning in King Saud university, Saudi Arabia," The Turkish Online Journal of Educational Technology - TOJET, vol. 8, 2009.

[10] Harrison, Rachel, Derek Flood, and David Duce. (2013, May). "Usability of mobile applications: literature review and rationale for a new usability model." Journal of Interaction Science [Online]. 1(1), pp.1-16. http://dx.doi.org/10.1186/2194-0827-1-1

[11] Vogel, Doug, David M. Kennedy, Kevin Kuan, Ron Kwok, and Jean Lai (2007). Do Mobile Device Applications Affect Learning? 2007 40th Annual Hawaii International Conference on System Sciences (HICSS'07), 4-4.

\section{AUTHORS}

Maha Alqahtani is a teaching assistant at the Information Systems Department. She is in the final stage of her Master's degree in Information Systems (e-mail: maha.al_qahtani@ccis.imamu.edu.sa).

Ayham Fayyoumi is an Assistant Professor of Information Systems at the College of Computer and Information Sciences. His research focuses on e-Learning, online exam systems, knowledge management, and eBusiness. He is the head of the Scientific Advisory Committee responsible for improving courses contents according to international scientific and quality standards, and a member of the Quality Assurance Committee responsible for ABET accreditation. He also provides different consultation services to various institutions (e-mail: a.fayyoumi@gmail.com).

Submitted 21 September 2014. Published as resubmitted by the authors 25 January 2015. 